\title{
Ocular Pathology Recommendations during COVID-19 from the American Association of Ophthalmic Oncologists and Pathologists (AAOOP)
}

\author{
Patricia Chévez-Barrios $^{a}$ Tatyana Milman ${ }^{b}$ Hans E. Grossniklaus ${ }^{c}$ Robert Folberg ${ }^{d}$ \\ Diva Regina Salomão ${ }^{\text {e Dan S. Gombos }}{ }^{f}$ \\ ${ }^{a}$ Houston Methodist Hospital, Houston, TX, USA; ${ }^{b}$ Wills Eye Hospital and Jefferson University Hospital, Philadelphia, PA,

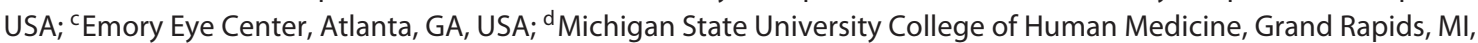 \\ USA; ${ }^{\mathrm{e}}$ Mayo Clinic, Rochester, MN, USA; ${ }^{f}$ University of Texas MD Anderson Cancer Center, Houston, TX, USA
}

Dear Editor,

With the COVID-19 outbreak, ocular pathologists must be particularly aware of exposure to the virus in their practice. Any specimen could be a source of infection $[1,2]$.

General pathologists have described cases in which patients who were asymptomatic and had lung resections for tumor subsequently tested positive for COVID-19.

No transmission to pathologists has been documented as of the time of submission of these recommendations, but it is essential that we protect ourselves from the possibility of exposure.

The highest risk of exposure exists during frozen section, when handling fresh, unfixed tissue. In the general pathology scenario, lung/respiratory, nasal, and oral mucosa specimens are the most critical specimens to be protected against. All personnel (trainees, staff, pathology assistants, and histotechnologists) in frozen section areas should wear personal protective equipment, at least surgical masks and eye protective glasses, but preferably N95 masks when handling these specimens. Wearing at least a surgical mask when handling fresh lung tissue has always been recommended, long before COVID-19.
Frozen sections for ocular pathology specimens of highest risk would be conjunctiva, nasolacrimal system, nasal, and sinus specimens - but any other fresh ocular tissue is potentially infectious.

When a frozen section is needed (a situation in which the surgical plan would change depending on the intraoperative diagnosis) and indicated for conjunctiva, nasolacrimal system, nasal, and sinus specimens, the same precautions should be taken as for respiratory specimens:

- All trainees, staff, pathology assistants, and histotechnologists in frozen section areas should don personal protective equipment, at least surgical masks, but preferably N95 masks when handling these specimens.

- It is also recommended that ocular pathologists adhere to their own frozen section's laboratory guidelines for the era of COVID-19 for any specimens they process.

It is recommended that all handling of fresh tissues occur in the operating room at the time of submitting the specimens for testing, as detailed in the following scenarios.

\section{KARGER}

(C) 2020 S. Karger AG, Basel

karger@karger.com

www.karger.com/oop
Patricia Chévez-Barrios, MD

Chair in Ocular Pathology, Department of Pathology and Genomic Medicine Houston Methodist Hospital, 6565 Fannin St, M227

Houston, TX 77030 (USA)

pchevez-barrios@houstonmethodist.org 
In ocular specimens where there is a need to exclude infectious process:

- the specimen should be divided in the operating room into the specimen for Microbiology and the specimen for Surgical Pathology.

- Submit the fresh specimen to microbiology directly (not to frozen sections or pathology) and place the other specimen immediately in formalin for pathology.

In ocular specimens where there is a need to perform flow cytometry or molecular testing:

- the specimen should be divided in the operating room into the specimen for Flow Cytometry/Molecular and the specimen for Surgical Pathology.

- Submit the fresh specimen to Flow Cytometry (in RPMI or in a wet TELFA paper with a balanced salt solution) or Molecular (in a sterile container, dry) directly to the appropriate laboratory (not to frozen sections for the pathologist to divide) and place the other specimen immediately in formalin for Surgical Pathology.

Always follow the guidelines of your own pathology department, but these are specific common scenarios in which specimens in eye pathology should be considered for special handling.

For up-to-date guidelines on CDC recommendations for laboratory COVID-19 biosafety please refer to the following website link:

https://www.cdc.gov/coronavirus/2019-ncov/lab/labbiosafety-guidelines.html

\section{Acknowledgement}

This document has been endorsed by the American Association of Ophthalmic Oncologists and Pathologists (AAOOP) Board of Directors. These recommendations are available at the AAOOP website: http://www.aaoop.org/. Reprint with permission from the American Association of Ophthalmic Oncologists and Pathologists (AAOOP).

\section{Disclosure Statement}

The authors have no conflicts of interest to declare.

\section{Funding Sources}

No funding source for this work.

\section{Author Contributions}

All authors contributed equally to final statements and form of the manuscript.

\section{References}

1 World Health Organization [Internet]. Laboratory Biosafety Manual [cited 2003]. https://www.who.int/csr/resources/publications/biosafety/ Biosafety7.pdf?ua $=1$

2 World Health Organization [Internet]. Laboratory biosafety guidance related to the novel coronavirus (2019-nCoV) [cited February 12, 2020]. https://www.who.int/docs/default-source/coronaviruse/laboratory-biosafety-novel-coronavirus-version-1-1.pdf?sfvrsn=912a9847_2 